\title{
Empowerment as a strategy to achieve the competitive advantage of organizations: A mediating role of organizational learning
}

\author{
Rabab Ibrahim Kadhim ${ }^{a *}$, Mhsen Alwan Mohammed ${ }^{b}$ and Hameedah Ghjaer Gremikh ${ }^{c}$
}

${ }^{a}$ Assistant Lecturer, Department of finance and banking sciences, Collage of Administration \&Economics, AL-Qadisiyah University, Iraq

${ }^{b}$ Assistant Lecturer, Department of Business Administration, Collage of Administration \&Economics, AL-Qadisiyah University, Iraq ${ }^{c}$ Assistant Lecturer, Collage of Administration \&Economics, Department of Business Administration, AL-Qadisiyah University, Iraq

CH RON I C L E

Article history:

Received: March 23, 2018

Received in revised format: June

21,2018

Accepted: June 21, 2018

Available online:

June 22, 2018

Keywords:

Organizational learning

Competitive advantage

Empowerment

Iraq

\begin{abstract}
A B S T R A C T
In this era of industrialization, it is very difficult for firms to develop and sustain the competitive advantage. Industrial competition spread so rapidly worldwide, which neglect the differentiation of products and it is very difficult to sustain the competitive advantage in the market. Large economies capture the maximum world market and give tough time to small economies such as Iraq. Thus, the primary aim of the current study is to present a comprehensive theoretical framework for competitive advantage, which leads to better firm performance. Many studies have highlighted the area of competitive advantage of the firms, however, in a rare instance, literature has reported limited discussion on sustainable competitive advantage, especially in the context of Iraq. This research gap formulated four hypotheses, which are proposed the relationship between empowerment strategy, organizational learning and competitive advantage. The pick and drop method was adopted to distribute the questionnaires among four hundred manufacturing firms of Iraq. The results of the current study found a positive and significant relationship between empowerment, organizational learning and competitive advantage. Furthermore, the current study found a significant relationship between empowerment strategy and organizational learning. Moreover, organizational learning was found the main contributory factor between empowerment strategy and competitive advantage in Iraq industrial context. This work contributes to the consistency of knowledge by developing a comprehensive theoretical account to build and sustain the competitive advantage of Iraq industry. Hence, the current work is helpful for sustainable competitive advantage of companies to achieve the highest firm performance.
\end{abstract}

\section{Introduction}

In this advanced era, nearly all organizations are faced with a dynamic environment characterized by rapid technological change, shortening product life cycles, and globalizations. The organizational bodies need to become more creative and innovative than ever before to survive, to compete, to grow, and to lead (Jung et al., 2005). In an increasingly competitive environment, companies are flexing to take strategic steps to improve the performance, market share, market exposure and potential of revenue earning (Barrio et al., 2011). Furthermore, Bolden (2016) stated that organizations are increasingly placing more resources for the growth of organizational functioning. Nevertheless, the manufacturing sector of Iraq

* Corresponding author.

E-mail address: fawtem.ali@gmail.com (R. I. Kadhim) 
holds an important role in the country's economy, which is contributing around $40 \%$ of gross domestic product (CIA, 2018). Moreover, the manufacturing sector in Iraq comes have been under pressure and facing many challenges from 1990 until now (Hafedh et al., 2007). Furthermore, previous reports have shown the low performance of the manufacturing sector in Iraq as well (Bureihi, 2011). This sector is performing poorly due to the low competitive advantage (Al-Naser \& Mohamed, 2017). Furthermore, the absence of Iraq in the world competitiveness report showing the low level of competitiveness of Iraq industry. The competitive advantage provides many benefits, such as an effective source for attaining superior performance and creating value for the organizations (Vanpoucke et al., 2014). Consequently, manufacturing companies are looking for strategic step which can provide them sustainable competitive advantage.

There are many researchers found the critical factors which constitute a contributing part in sustainable competitive advantage such as export business strategy (Leonidou et al., 2015); marketing capabilities (Tan \& Sousa, 2015); human resource management practices (Albrecht et al., 2015); dynamic capabilities (Li \& Liu, 2014); information technology and knowledge management (Mao et al., 2016); employee empowerment (Ghosh, 2013) and organizational learning (Zulkarnain et al., 2016). Yet, Francescato and Aber (2015) stated that empowerment is (a) to offer the opportunity for advancement, (b) to access to information, (c) to access to funding, and (d) the opportunity to develop and discover. Furthermore, many researchers found a positive and significant influence of empowerment on sustainable competitive advantage (del Brío et al., 2007; Ghosh, 2013). Furthermore, in respect to organizational learning that the learning process occurs, there is a change in the ideas and points of view in the organization. These changes are producing novel thoughts and viewpoints through communication and interaction with the system. Organizational learning is one of the most important fundamentals to hold a sustainable competitive advantage (Ramin et al., 2013). Nevertheless, these factors such as empowerment and organizational learning considered a significant factor in the past literature. Therefore, the main objective is to investigate the influence of empowerment and organizational learning on competitive advantage in the context of the Iraq's manufacturing sector, where the performance was recorded poorly. Furthermore, very limited studies explained the relationship between empowerment and competitive advantage.

\section{Literature review}

\subsection{Competitive Advantage}

Spender and Kraaijenbrink (2011) stated that without value creation in products organizations do not survive in the marketplace. The value creation can improve organizational performance by maximizing net income per share, making sure the level of functional effectiveness and allows systems to stay competitive (Gholami, 2011). Hence, the creation of values indirectly helps organizations implement a strategy to better efficiency and competitiveness (Porter, 1997). Additionally, firms have difficulty in achieving sustainability and cope with rapid changes in the dynamic environment due to globalization and increased competition. Consequently, organizations must be able to extend or to create something new to differentiate themselves from their rivals. According to Prieto et al. (2009) organizations can offer something different in the market and have the potential to attain superior execution and create value. Thus, many authors suggested that organizations should present the strategic plan which introduce the different and unique products and service than competitors.

\subsection{Empowerment and competitive advantage}

Empowerment often have assigned rather easily as giving power to people that they can make decisions in the organization. Indeed, even in the empowered organization, the manager still determines the way of company goals for organizational performance. Randolph and Sashkin (2002) observed that empowerment is to understand and to deliver to organization the power that people sustain their wealth of useful knowledge, experience, and motivation. Further, they told that organizational management has difficulty with the idea of providing control, fearing that organizational performance will be weaken if they let employees take over. On the other hand, employees thought the empowerment sounds great, if they do 
not have to take personal responsibility for the results. Their life experiences in command and control of the organization made some employees who are afraid to take the risk of liability, where failure is as much a possibility as a success but with potentially large negative consequences. Indeed, employees fear the responsibility, especially improved in some culture that perpetuates the idea that it is the job of the manager (and not the employee) to make decisions and take responsibility for results. Lawler et al. (2001) presented that when people are given more control and responsibility, the company achieve greater return on sales (10.3 percent) than in companies that do not involve people (6.3 percent). However, empowerment strategy has existed in many companies such as Wal-Mart, VISA and Trader Joe's. The Trader Joe's, a company in the retail food industry, found that more empowerment increased annual sales growth of 15 percent to 26 percent. Sales per store increased 10 percent per year, while the number of stores increased almost 100 percent (Randolph \& Sashkin, 2002).

In the past studies, many authors empirically proved that empower has an influential impact on competitive advantage (Brío et al., 2007). In addition, Ghosh (2013) investigated the relationship between empowerment strategy and industrial competitive advantage in the context of India and found positive and significant influence of empowerment on competitive advantage. In another study researcher found the significant role of empowerment in sustainable competitive advantage in the context of Iran's industry (Kahreh et al., 2011). Therefore, past literature motivates to current studies that empowerment strategy will influence to industrial competitive advantage, thus current proposing the following hypothesis to validate the relationship in the context of Iraq.

H1: The empowerment strategy positively influences on competitive advantage.

\subsection{Organizational learning and competitive advantage}

The learning process occurs when there is a change in the ideas and points of view in the organization (Purhaghshenas \& Esmatnia, 2012). These changes create new ideas and viewpoints through communication and interaction with the organization. Organizational learning emphasizes on the development and adaptation of knowledge within the organization, while the learning organization focuses on the acquisition of knowledge and skills by employees of the organization (Mavondo et al., 2005). Levitt and March (1988) described that organizational learning enables an organization to achieve continuous improvement and enhance the knowledge, skills and attitudes and thus achieve value creation, which is leading to competitive advantage. The organizational learning is one of the most important requirements to obtain a sustainable competitive advantage (Ramin et al., 2013). In addition, according to Singh (2011) organizational learning is a long-term activity that contributes to the achievement of competitive advantage.

Furthermore, Lei et al. (2017) and Liao at al. (2017) investigated the relationship between organizational learning and competitive advantage in the context of Taiwan and found the contributory role of organizational learning into a firm competitive advantage. In another study, the authors found a positive and significant relationship between organizational learning and competitive advantage (Zulkarnain et al., 2016). Therefore, above discussed literature show the contributory role of organizational learning in firm competitive advantage against competitors, hence organizational learning can sustain the competitive advantage in the context of Iraq, where low competition recorder. Thus, the following hypothesis is proposed.

H2: The organizational learning positively influences on competitive advantage.

\subsection{Empowerment strategy and organizational learning}

Elements associated with empowerment usually include delegation of authority, motivation, job development, autonomy, self-leadership, high-engagement and participatory management, although these elements do not appear in practice (Spreitzer, 2008). Empowerment affects organizational learning in a 
variety of ways, such as employees can evaluate the effectiveness of their works and to recommend measures for improvement, and replacing the old routines with new one. Employees are no longer just concerned with how to effectively complete the tasks prescribed, but they became actively involved with the underlying mental models, norms, policies and assumptions of their works, thereby increasing the reflection and learning (Randolph \& Sashkin, 2002). It seems the empowerment that improves the development of new knowledge because it allows member organizations to develop their own ideas and practices and adapt to the current state of the local (Santos-Vijande et al., 2012).

Moreover, Van Grinsven and Visser (2011) stated that empowerment strategy effect on organizational learning in a positive sense. Similarly, Gutierrez-Gutierrez et al. (2018) investigated the relationship between empowerment and organizational learning in the context of European firms and found the positive relationship between two constructs. Therefore, it seems that the empowerment that positively affects the learning organization. Thus, the following hypothesis is proposed.

H3: The empowerment strategy positively influences on organizational learning.

\subsection{Organisational learning as a mediator}

Moreover, some of researchers investigated the organizational learning mediating role between two constructs. Liao et al. (2017) found the organizational learning played a mediating role between absorptive capability and competitive advantage. In the study Hsu and Fang (2009) found the indirect relationship between intellectual capital and new product development through organizational learning. Additionally, the author reported the mediating role of organizational learning between entrepreneurial orientation and firm performance (Real et al., 2014). Thus, previous findings regarding the mediating role of organizational learning stated that organizational learning can be the effective mediator between empowerment and competitive advantage to clarify the relationship.

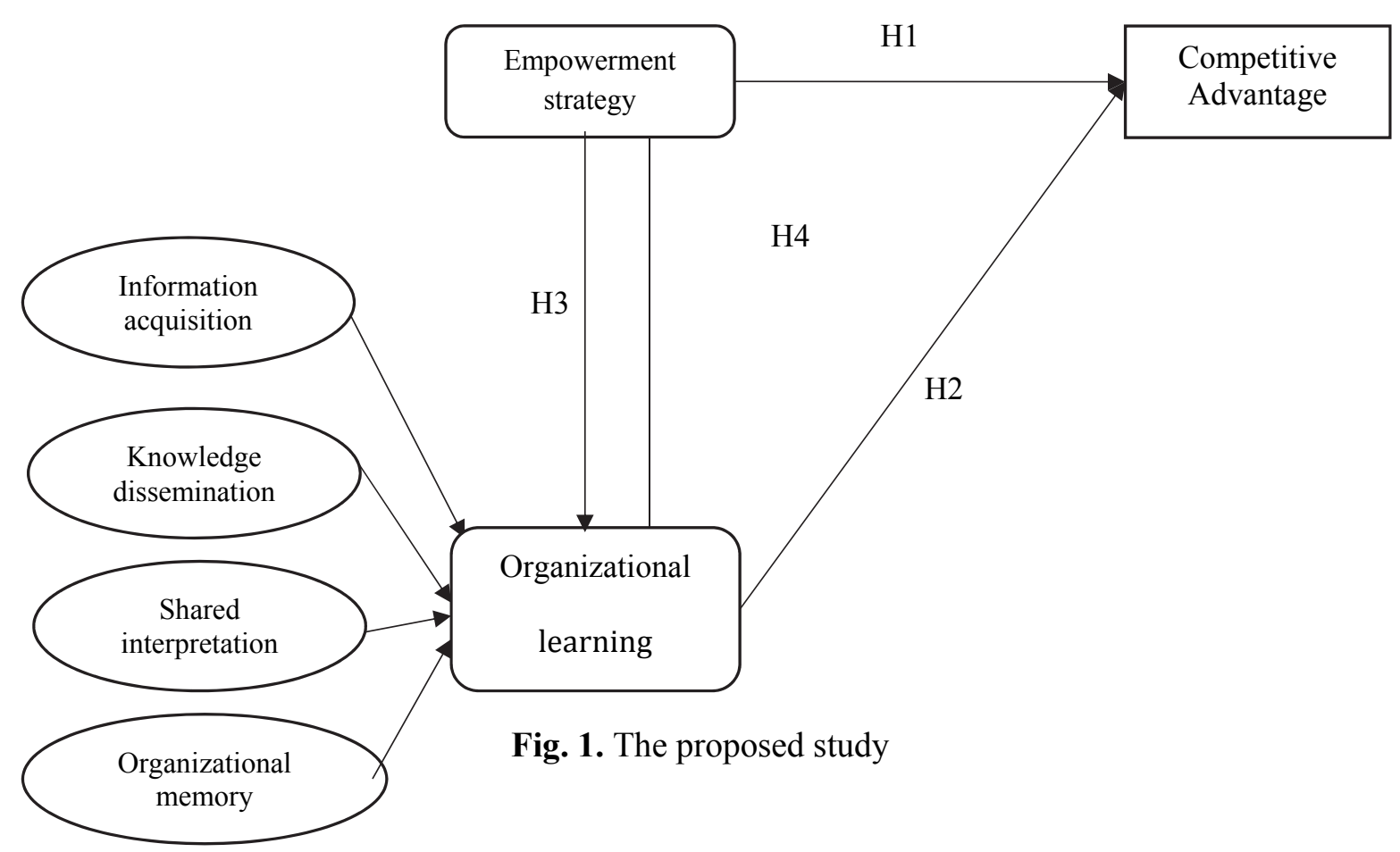

The empowerment strategy helps the organizations learn and gain competitive advantage. In this relationship organization, learning takes input from empowerment strategy and gives output in term of sustainable competitive advantage. More specifically, in this current study, organizational learning plays a dynamic capability role that integrated, configured and developed the resources according to business 
environment and maintained the sustainable competitive advantage (Teece et al., 1997). Some of researchers also operationalized the organizational learning as a dynamic capability as well (Camisón \& Villar-López, 2011; Gutierrez-Gutierrez et al., 2018; Santos-Vijande et al., 2012). Therefore, the dynamic nature of organizational learning plays the mediating role between empowerment and competitive advantage. Hence the following hypothesis is proposed.

H4: The relationship between empowerment strategy and competitive advantage is mediated by organizational learning.

\section{Methodology}

The selection of suitable technique for the analysis should be based on the type of problem (Imran et al., 2017; Imran et al., 2018; Imran et al., 2018). The current survey is based on quantitative research approach. Nevertheless, in conformity with the nature of the study, cross-sectional design was chosen. A study was directed to gather the data from an owner / manager of manufacturing firms in Iraq. The 7point Likert scale was used to gather the information. Measures of the constructs were adapted from past studies. The empowerment strategy scale was adapted from the study of Sok and O'Cass (2015) with 12 items. Meanwhile, organizational learning was adapted from Santos-Vijande et al. (2012), which consists of several dimensions such as information acquisition (11 items), knowledge dissemination (7 items), shared interpretation ( 7 items) and organizational memory ( 7 items). Finally, the competitive advantage scale was adapted from the study of $\mathrm{Li}$ et al. (2006) with five dimensions such as price (2 items), quality (4 items), delivery dependability ( 3 items), product innovation (3 items) and time to market (4 items). The pick and drop method was performed, and questionnaires were distributed by using simple random sampling technique. The sample size was chosen based on Krejcie and Morgan (1970) table. According to Krejcie and Morgan (1970) sample size table that two hundred ninety (290) the sample size was elected in the current study. The response rate is given in Table 1. Moreover, SmartPLS 3 (SEM) was applied to examine the gathered information.

\section{Table 1}

\begin{tabular}{|c|c|c|c|}
\hline Response & Frequency/Rate & Response & Frequency/Rate \\
\hline Number of questionnaires given out & 400 & Number of excluded questionnaires & 20 \\
\hline Number of questionnaires returned & 310 & Response rate before data entry & $77.50 \%$ \\
\hline Number of Useable questionnaires & 290 & Response rate after data entry & $72.50 \%$ \\
\hline
\end{tabular}

\section{Data Analysis and Results}

\subsection{Measurement Model Assessment for reflective construct}

SmartPLS 3 was used to assess the measurement model. In this process factor internal consistency, Cronbach's alpha, composite reliability and average variance extracted (AVE) were studied. Fig. 1 demonstrates the measurement model assessment of reflective constructs the first order. The outcomes of the measurement model assessment are presented in Table 2. The outcomes indicate that all they have achieved the threshold value 0.70 . According to Hair Jr et al. (2016), factor loading should be more than 0.50 and all those items should be deleted with factor loading less than 0.50 . Internal consistency is accomplished as the factor loading is more than 0.50 which confirms the convergent validity. Composite reliability and AVE are also more than acceptable range 0.70 and 0.50 , respectively (Fornell \& Larcker, 1981; Hair Jr et al., 2016). Moreover, for the discriminant validity we have used the Fornell and Larcker (1981) criteria to confirm the external consistency and Table 3 shows the results of discriminant validity. 


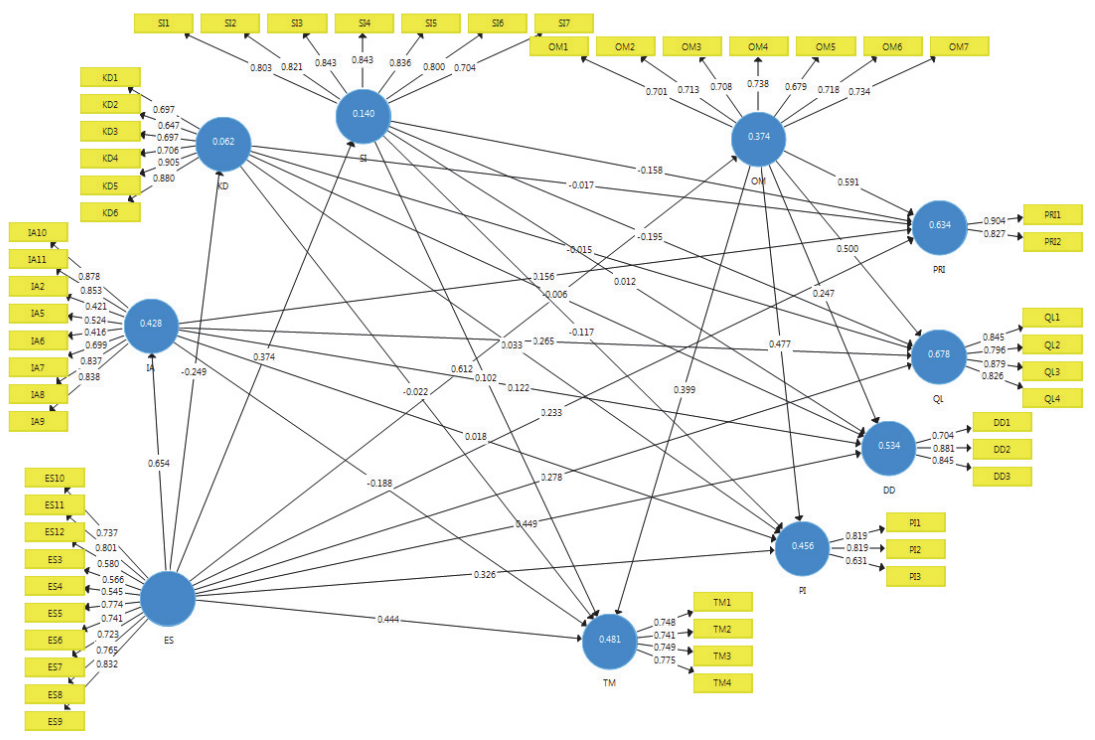

Fig. 2. Measurement Model Assessment (Reflective $1^{\text {st }}$ order)

Table 2

Factor Loading, Cronbach's alpha, Composite reliability and AVE

\begin{tabular}{lccc}
\hline Construct & Cronbach's Alpha & Composite Reliability & Average Variance Extracted (AVE) \\
\hline DD & 0.743 & 0.853 & 0.661 \\
ES & 0.889 & 0.91 & 0.509 \\
IA & 0.867 & 0.882 & 0.502 \\
KD & 0.921 & 0.891 & 0.580 \\
OM & 0.845 & 0.879 & 0.509 \\
PI & 0.646 & 0.803 & 0.580 \\
PRI & 0.673 & 0.857 & 0.751 \\
QL & 0.857 & 0.903 & 0.701 \\
SI & 0.911 & 0.929 & 0.653 \\
TM & 0.746 & 0.84 & 0.568 \\
\hline
\end{tabular}

Note: DD: Delivery dependability, ES: empowerment strategy, IA: information acquisition, KD: knowledge dissemination, OM: organizational memory, PI: product innovation, PRI: price, QL: quality, SI: shared interpretation, TM: time to market

Table 3

Discriminant Validity

\begin{tabular}{|c|c|c|c|c|c|c|c|c|c|c|}
\hline & DD & ES & IA & $\mathrm{KD}$ & $\mathrm{OM}$ & PI & PRI & $\mathrm{QL}$ & SI & TM \\
\hline $\mathrm{DD}$ & 0.813 & & & & & & & & & \\
\hline ES & 0.686 & 0.713 & & & & & & & & \\
\hline IA & 0.582 & 0.654 & 0.708 & & & & & & & \\
\hline KD & -0.135 & -0.249 & -0.184 & 0.762 & & & & & & \\
\hline $\mathrm{OM}$ & 0.608 & 0.612 & 0.649 & 0.015 & 0.713 & & & & & \\
\hline PI & 0.624 & 0.577 & 0.486 & -0.059 & 0.620 & 0.762 & & & & \\
\hline PRI & 0.627 & 0.642 & 0.629 & -0.115 & 0.741 & 0.658 & 0.866 & & & \\
\hline QL & 0.724 & 0.687 & 0.692 & -0.15 & 0.726 & 0.673 & 0.821 & 0.837 & & \\
\hline SI & 0.375 & 0.374 & 0.417 & 0.125 & 0.588 & 0.297 & 0.340 & 0.311 & 0.808 & \\
\hline TM & 0.522 & 0.608 & 0.407 & -0.079 & 0.608 & 0.628 & 0.569 & 0.531 & 0.421 & 0.753 \\
\hline
\end{tabular}

Note: DD: Delivery dependability, ES: empowerment strategy, IA: information acquisition, KD: knowledge dissemination, OM: organizational memory, PI: product innovation, PRI: price, QL: quality, SI: shared interpretation, TM: time to market

\subsection{Measurement Model Assessment for formative constructs}

The formative measurement model was evaluated through multicollinearity among items and analysis of their weights (Hair Jr et al., 2017). Maximum variance inflation factor (VIF) value for each formative indicator was computed and found all values less than threshold values 5 (Hair Jr et al., 2016). Secondly, 
we have checked the significance of weights with a resampling procedure and found the significance values of outer weights and as well as outer loading. Hence the measurement model for formative construct second order was validated. The results can be seen in the Table 4.

Table 4

Formative construct ( $2^{\text {nd }}$ order) assessment of measurement model

\begin{tabular}{lllllll}
\hline \multirow{2}{*}{ Constructs } & Indicator & $\begin{array}{l}\text { Outer } \\
\text { loading }\end{array}$ & $\begin{array}{l}\text { OL } \\
\text { T-Value }\end{array}$ & $\begin{array}{l}\text { Outer } \\
\text { Weights }\end{array}$ & $\begin{array}{l}\text { OW } \\
\text { T-Value }\end{array}$ & \multicolumn{1}{c}{ VIF } \\
\hline \multirow{3}{*}{ Organizational learning (OL) } & Information acquisition & 0.424 & $6.879^{* *}$ & 0.871 & $32.707^{* *}$ & 1.864 \\
& Knowledge dissemination & 0.176 & $4.287^{* *}$ & 0.249 & $3.260^{* *}$ & 1.099 \\
& Shared interpretation & 0.036 & $0.579^{\text {ns }}$ & 0.508 & $7.785^{* *}$ & 1.577 \\
& Organizational memory & 0.662 & $9.394^{* *}$ & 0.913 & $41.718^{* *}$ & 2.206 \\
\hline & Price & 0.274 & $3.457^{* *}$ & 0.894 & $42.471^{* *}$ & 3.392 \\
& Quality & 0.412 & $4.497^{* *}$ & 0.934 & $52.401^{* *}$ & 4.067 \\
\cline { 2 - 6 } & Product innovation & 0.011 & $0.163^{\text {ns }}$ & 0.749 & $20.017^{* *}$ & 2.384 \\
& Delivery & 0.248 & $3.904^{* *}$ & 0.834 & $32.707^{* *}$ & 2.307 \\
& Time to market & 0.233 & $4.007^{* *}$ & 0.731 & $15.701^{* *}$ & 1.810 \\
\hline
\end{tabular}

\subsection{Structural Model Assessment}

Table 5 shows the direct relationship results. It is found that all the direct relationships have t-value more than 1.96 at 0.05 significance level. Therefore, all the relationships found positive significant. Therefore, hypothesis such as H1, H2, H3 are accepted. Moreover, Table 5 presents the effect size (f2). By pursuing the recommendations of Cohen (1988), it is found that empowerment and organizational learning are medium and large effect size (f2), respectively. Furthermore, empowerment has a substantial effect (f2) in organizational learning.

Table 5

Direct Results

\begin{tabular}{cccccccc}
\hline Hypothesis & & $\beta$-value & $($ STDEV $)$ & T Statistics & P-Values & $\mathrm{f}^{2}$ & Decision \\
\hline $\mathrm{H}-1$ & ES $\rightarrow$ CA & 0.358 & 0.047 & 7.616 & 0.000 & 0.249 & Accepted \\
H-2 & OL $\rightarrow$ CA & 0.571 & 0.044 & 12.959 & 0.000 & 0.633 & Accepted \\
H-3 & ES $\rightarrow$ OL & 0.713 & 0.032 & 22.285 & 0.000 & 1.033 & Accepted \\
\hline Note $* * \mathrm{p}<0.1, * \mathrm{p}<0.05, \mathrm{NS}=$ not significant & $(\mathrm{p}>05)$ & & & &
\end{tabular}

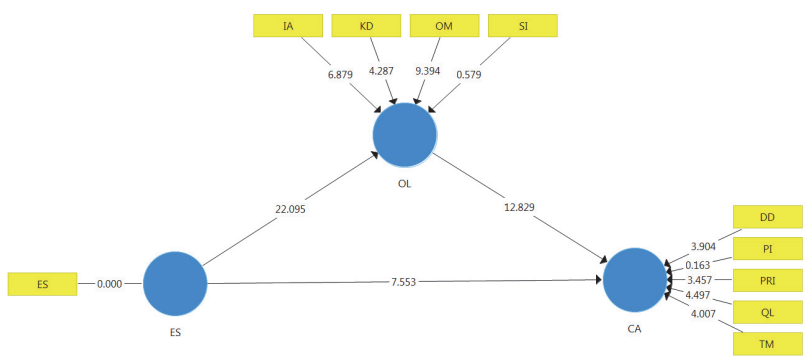

Fig. 3. The results of the impacts of ES, CA and OL

Furthermore, Table 6 shows the results of measurement model assessment indirect effects. It is found that the mediation effect is significant with $t$-value 11.362 with positive $\beta$-value. Thus, organizational learning is a mediating variable between empowerment strategy (ES) and competitive advantage (CA). Hence, $\mathrm{H}-4$ is accepted.

Table 6

Mediations (indirect effect) Results

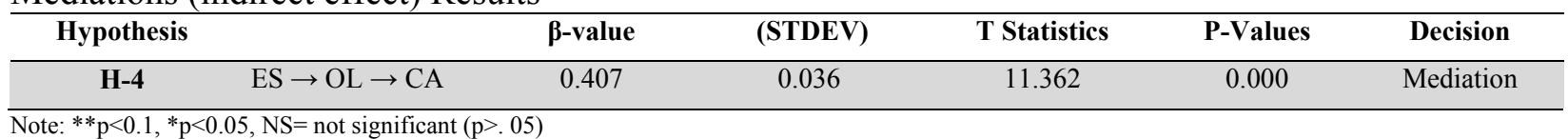


Nevertheless, according to Chin (1998), $R^{2}$ above 0.30 is considered moderate. Nevertheless, the current study found the R-value is 0.746 which is substantial. It shows that all the set of independent variables is expected to explain $74.6 \%$ dependent variable (competitive advantage).

\section{Findings}

In specifically, the t-value greater than the threshold value of 1.96 with significant value at 0.05 is acceptable. The path between ES and CA $(\beta=0.358$, $t$-value $=7.616, p<0.05)$, indicates a positive significant relationship. Thus, the current survey found a significant positive relationship between ES and CA, supporting H1. It shows that an increase in one variable will also increase in another variable with the same direction. In the respect of OL and $\mathrm{CA}(\beta=0.571$, $\mathrm{t}$-value $=12.959, \mathrm{p}<0.05)$, values show a positive significant relationship between two constructs, further beta indicating that $57 \%$ contribution of $\mathrm{CA}$. Therefore, finding is presented the positive significant relationship between OL and CA, thus offering support for $\mathrm{H} 2$. In respect to relationship between $\mathrm{ES}$ and $\mathrm{OL}(\beta=0.713$, $\mathrm{t}$-value $=22.285, \mathrm{p}<0.05)$, it shows a positive and significance relationship and beta indicating $71 \%$ change in organizational learning. Thus, we have found support for H3. At last, the mediation role of OL between ES and CA $(\beta=0.407$, tvalue $=11.362, p<0.05)$, values show a strong mediation role of OL between ES and CA. In respect of mediation type, the current study found the complementary mediation (partial mediation). Thus, current study results demonstrate the OL mediating role between ES and CA. Hence, H6 found support.

\section{Conclusion}

In this study, it has been observed that competitive advantage is one of the critical elements for the economic development of any country. It is most important for the Iraq economic development. Complementary intention towards industry competitive advantage can raise the individual, firm performance and as well as well industry performance. Furthermore, CA can increase the customer satisfaction level, which is a problematic area in the industry of Iraq. Nevertheless, the CA in Iraq can improve through the effective usage of empowerment strategy and organizational learning. Therefore, the current study, findings also guaranty that empowerment strategy and organizational learning, playing a contributing role in competitive advantage. Moreover, the study results presented that organizational learning was acting like a bridge between ES and CA. OL provides the latest business, environmental knowledge to the firm and help to organizational in term to develop and integrate the resources such as empowerment strategy, according to dynamic business environment, which is giving a sustainable competitive advantage. However, OL is helpful to manage the firm resources and sustained the competitive advantage in Iraq context. Therefore, by the assistance of OL, it is possible to solve Iraq industrial competitive advantage problems through providing latest information regarding dynamic environment and reduce the complexity of information. Hence, OL is one of the promising dynamic capability to mitigate different problems and to increase competitive advantage. Thus, the current study suggested that for sustainable industrial competitive advantage, owner / manager and policy makers should invest on employee empowerment and organizational learning resource and capability. Future research in this context can be more beneficial for manufacturing products, competitive advantage of Iraq. The current research field is restricted to two factors related to CA, further study should explore the other factor such total quality management (TQM), entrepreneurial orientation (EO) and technological advancement (TA).

\section{References}

Al-Naser, K., \& Mohamed, R. (2017). The Integration between Strategic Cost Management Techniques to Improve the Performance of Iraqi Manufacturing Companies. Asian Journal of Finance \& Accounting, 9(1), $210-223$.

Albrecht, S. L., Bakker, A. B., Gruman, J. A., Macey, W. H., \& Saks, A. M. (2015). Employee engagement, human resource management practices and competitive advantage: An integrated approach. Journal of Organizational Effectiveness: People and Performance, 2(1), 7-35.

Barrio, D., García, S., \& Solís, J. P. (2011). Management model for technological innovation in real estate. Revista Ingeniería de Construcción, 26(3), 353-368. 
Bolden, R. (2016). Leadership, management and organisational development Gower handbook of leadership and management development (pp. 143-158): Routledge.

Bureihi, F. (2011). Iraqi economy ... opportunities and challenges. Baghdad College of Economic Sciences University Journal, 27, 21-56.

Camisón, C., \& Villar-López, A. (2011). Non-technical innovation: organizational memory and learning capabilities as antecedent factors with effects on sustained competitive advantage. Industrial Marketing Management, 40(8), 1294-1304.

Chin, W. W. (1998). The partial least squares approach to structural equation modeling. Modern methods for business research, 295(2), 295-336.

CIA. (2018). The Wolrd Factbook. Retrieved from https://www.cia.gov/library/publications/resources/the-worldfactbook/geos/iz.html

del Brío, J. Á., Fernandez, E., \& Junquera, B. (2007). Management and employee involvement in achieving an environmental action-based competitive advantage: an empirical study. The International Journal of Human Resource Management, 18(4), 491-522.

Fornell, C., \& Larcker, D. F. (1981). Evaluating structural equation models with unobservable variables and measurement error. Journal of Marketing Research, 39-50.

Francescato, D., \& Aber, M. S. (2015). Learning from organizational theory to build organizational empowerment. Journal of Community Psychology, 43(6), 717-738.

Gholami, S. (2011). Value creation model through corporate social responsibility (CSR). International Journal of Business and Management, 6(9), 148.

Ghosh, A. K. (2013). Employee empowerment: A strategic tool to obtain sustainable competitive advantage. International Journal of Management, 30(3), 95.

Gutierrez-Gutierrez, L. J., Barrales-Molina, V., \& Kaynak, H. (2018). The role of human resource-related quality management practices in new product development: A dynamic capability perspective. International Journal of Operations \& Production Management, 38(1), 43-66.

Hafedh, M., Akoum, I., Zbib, I. J., \& Ahmed, Z. U. (2007). Iraq: emergence of a new nation from the ashes. International Journal of Emerging Markets, 2(1), 7-21.

Hair Jr, J. F., Hult, G. T. M., Ringle, C., \& Sarstedt, M. (2016). A primer on partial least squares structural equation modeling (PLS-SEM): Sage Publications.

Hair Jr, J. F., Sarstedt, M., Ringle, C. M., \& Gudergan, S. P. (2017). Advanced issues in partial least squares structural equation modeling: SAGE Publications.

Hsu, Y.-H., \& Fang, W. (2009). Intellectual capital and new product development performance: The mediating role of organizational learning capability. Technological Forecasting and Social Change, 76(5), 664-677.

Imran, M., Aziz, A., \& Hamid, S. (2017). Determinants of SME export performance. International Journal of Data and Network Science, 1(2), 39-58.

Imran, M., Hamid, S., \& Aziz, A. (2018). The influence of TQM on export performance of SMEs: Empirical evidence from manufacturing sector in Pakistan using PLS-SEM. Management Science Letters, 8(5), 483-496.

Imran, M., Aziz, A., Hamid, S., Shabbir, M., Salman, R., \& Jian, Z. (2018). The mediating role of total quality management between entrepreneurial orientation and SMEs export performance. Management Science Letters, 8(6), 519-532.

Jung, R. E., Haier, R. J., Yeo, R. A., Rowland, L. M., Petropoulos, H., Levine, A. S., . . Brooks, W. M. (2005). Sex differences in N-acetylaspartate correlates of general intelligence: an 1H-MRS study of normal human brain. Neuroimage, 26(3), 965-972.

Kahreh, M. S., Ahmadi, H., \& Hashemi, A. (2011). Achieving competitive advantage through empowering employees: An empirical study. Far East Journal of Psychology and Business, 3(2), 26-37.

Krejcie, R. V., \& Morgan, D. W. (1970). Determining sample size for research activities. Educational and psychological measurement, 30(3), 607-610.

Lawler, E. E., Mohrman, S. A., \& Benson, G. (2001). Organizing for high performance: Employee involvement, $T Q M$, reengineering, and knowledge management in the Fortune 1000: The CEO report: Jossey-Bass.

Lei, H., Le, P. B., \& Nguyen, H. T. H. (2017). How Collaborative Culture Supports for Competitive Advantage: The Mediating Role of Organizational Learning. International Journal of Business Administration, 8(2), 73.

Leonidou, L. C., Fotiadis, T. A., Christodoulides, P., Spyropoulou, S., \& Katsikeas, C. S. (2015). Environmentally friendly export business strategy: Its determinants and effects on competitive advantage and performance. International Business Review, 24(5), 798-811.

Levitt, B., \& March, J. G. (1988). Organizational learning. Annual review of sociology, 14(1), 319-338. 
Li, D.-y., \& Liu, J. (2014). Dynamic capabilities, environmental dynamism, and competitive advantage: Evidence from China. Journal of Business Research, 67(1), 2793-2799.

Li, S., Ragu-Nathan, B., Ragu-Nathan, T., \& Rao, S. S. (2006). The impact of supply chain management practices on competitive advantage and organizational performance. Omega, 34(2), 107-124.

Liao, S.-H., Chen, C.-C., Hu, D.-C., Chung, Y.-c., \& Yang, M.-J. (2017). Developing a sustainable competitive advantage: absorptive capacity, knowledge transfer and organizational learning. The Journal of Technology Transfer, 42(6), 1431-1450.

Mao, H., Liu, S., Zhang, J., \& Deng, Z. (2016). Information technology resource, knowledge management capability, and competitive advantage: the moderating role of resource commitment. International Journal of Information Management, 36(6), 1062-1074.

Mavondo, F. T., Chimhanzi, J., \& Stewart, J. (2005). Learning orientation and market orientation: Relationship with innovation, human resource practices and performance. European Journal of Marketing, 39(11/12), 12351263.

Porter, M. E. (1997). Competitive strategy. Measuring Business Excellence, 1(2), 12-17.

Prieto, I. M., Revilla, E., \& Rodríguez-Prado, B. (2009). Building dynamic capabilities in product development: how do contextual antecedents matter? Scandinavian Journal of Management, 25(3), 313-326.

Purhaghshenas, S. H., \& Esmatnia, M. (2012). Learning organizations. Interdisciplinary Journal of Comtemporary Research in Business, 4(7), 243-249.

Ramin, N. A. M., Taib, K. M., Hashim, D. M., Noordin, S. A., \& Yasin, S. M. (2013). Knowledge management implementation in a government research institute in Selangor, Malaysia. Communications of the IBIMA, 2013, 1 .

Randolph, W. A., \& Sashkin, M. (2002). Can organizational empowerment work in multinational settings? The Academy of Management Executive, 16(1), 102-115.

Real, J. C., Roldán, J. L., \& Leal, A. (2014). From entrepreneurial orientation and learning orientation to business performance: analysing the mediating role of organizational learning and the moderating effects of organizational size. British Journal of Management, 25(2), 186-208.

Santos-Vijande, M. L., López-Sánchez, J. Á., \& Trespalacios, J. A. (2012). How organizational learning affects a firm's flexibility, competitive strategy, and performance. Journal of Business Research, 65(8), 1079-1089.

Singh, S. K. (2011). Leadership \& organizational learning in knowledge management practices in global organizations. Indian Journal of Industrial Relations, 353-365.

Sok, P., \& O'Cass, A. (2015). Achieving service quality through service innovation exploration-exploitation: the critical role of employee empowerment and slack resources. Journal of Services Marketing, 29(2), 137-149.

Spender, J., \& Kraaijenbrink, J. (2011). Why Competitive Strategy Succeeds-and With Whom. Competition, competitive advantage, and clusters: The ideas of Michael Porter, 33-55.

Spreitzer, G. M. (2008). Taking stock: A review of more than twenty years of research on empowerment at work. Handbook of organizational behavior, 1, 54-72.

Tan, Q., \& Sousa, C. M. (2015). Leveraging marketing capabilities into competitive advantage and export performance. International Marketing Review, 32(1), 78-102.

Teece, D. J., Pisano, G., \& Shuen, A. (1997). Dynamic capabilities and strategic management. Strategic Management Journal, 18(7), 509-533.

Van Grinsven, M., \& Visser, M. (2011). Empowerment, knowledge conversion and dimensions of organizational learning. The Learning Organization, 18(5), 378-391.

Vanpoucke, E., Vereecke, A., \& Wetzels, M. (2014). Developing supplier integration capabilities for sustainable competitive advantage: A dynamic capabilities approach. Journal of Operations Management, 32(7-8), 446461.

Zulkarnain, N. N., Abdullah, N., Herda, N., Said, J., \& Alam, M. (2016). Organizational learning orientation and sustainable competitive advantage: towards more accountable government-linked companies. Asia-Pacific Management Accounting Journal, 11(1), 96-113.

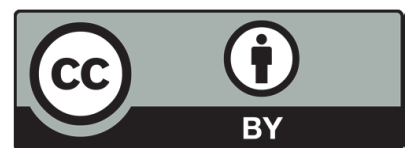

C 2018 by the authors; licensee Growing Science, Canada. This is an open access article distributed under the terms and conditions of the Creative Commons Attribution (CCBY) license (http://creativecommons.org/licenses/by/4.0/). 